\title{
Treatment of refractory uveitic macular edema: results of a first and second implant of long-acting intravitreal dexamethasone
}

This article was published in the following Dove Press journal:

Clinical Ophthalmology

6 November 2017

Number of times this article has been viewed

\section{Marta Zola \\ Cristina Briamonte \\ Umberto Lorenzi \\ Federica Machetta \\ Federico M Grignolo \\ Antonio M Fea}

Ophthalmic Eye Hospital, Department of Surgical Sciences, University of Turin, Italy
Correspondence: Marta Zola

$\mathrm{Tel}+4|2| 6268$ III

Email marta.zola@fa2.ch
Purpose: The purpose of this study was to report the functional and anatomical outcomes of a prospective study resulting from repeated dexamethasone intravitreal implants in patients with uveitic refractory macular edema.

Methods: Twelve eyes of 9 patients with intermediate and posterior noninfectious inflammatory uveitis complicated with refractory macular edema were regularly reviewed after a dexamethasone intravitreal implant. Patients were examined at baseline, 30, 90, 135, and 180 days with best-corrected visual acuity (BCVA), complete slit-lamp examination, intraocular pressure (IOP), optical coherence tomography, and fluorescein angiography. After 6 months of follow-up, eyes were reassessed to receive a second implant.

Results: BCVA significantly improved when comparing the baseline values after the first and second implant (16.2 and 25.8 letters, respectively, 9.6 letters improvements, $p<0.05$ ). BCVA was better after the second implant compared to the first one throughout the follow-up, but without statistical significance. Mean central macular thickness (CMT) was $446.3 \pm 129.9 \mu \mathrm{m}$ at baseline and was significantly reduced until day $135(p<0.05)$. CMT reductions after the second injection showed a similar pattern, though differences were not statistically significant. Cataract progression was observed in 4 of 8 phakic eyes $(50 \%)$ after the first implant, and in 2 of 3 phakic eyes following the second implant, with 1 eye requiring cataract surgery. One eye developed an IOP $>30 \mathrm{mmHg} 30$ days after the second implant, treated topically.

Conclusion: Repeated dexamethasone intravitreal implants in uveitic patients with refractory macular edema can be used effectively in a clinical setting with an acceptable safety profile.

Keywords: uveitis, macular edema, dexamethasone, intavitreal implant

\section{Introduction}

Uveitis is a group of inflammatory diseases of the eye accounting for $10 \%-15 \%$ of legally blind people in the Western world. ${ }^{1-3}$ Noninfectious uveitis is the most common cause of uveitis. The clinical presentation is often a chronic and/or recurrent inflammation, leading to the breakdown of the inner and outer blood-retinal barrier, to increased vessels permeability, swelling of the central retina, and cystoid macular edema (CME). Several factors are implicated, including increased levels of vascular endothelial growth factor, inflammatory mediators (prostaglandins, interleukin-6), as well as a reduction of the endothelial tight junctions. ${ }^{4-7}$ Corticosteroids were the mainstay in the treatment of uveitis, with considerable advances in the immunosuppressive therapy established in recent years. ${ }^{8,9}$ Steroids present important systemic and ocular side effects, the latter being increased intraocular pressure (IOP) with a varying range of $20.8 \%-52 \%$ and accelerated cataract formation in $29 \%$ of patients. ${ }^{10-15}$ The most 
effective route of administration of steroids is a matter of debate..$^{16,17,30}$ The Ozurdex ${ }^{\circledR}$ implant (Allergan, Inc, Irvine, CA, USA) injected into the vitreous chamber through a 22-gauge applicator has proved to be effective in treating macular edema from branch retinal vein occlusion/central retinal vein occlusion, as well as uveitis and other etiologies. ${ }^{18-22}$ The implant is a biodegradable copolymer composed of polylactic acid and polyglycolic acid that erodes into carbon dioxide and water, while dexamethasone is released into the eye. ${ }^{23,24}$

The purpose of this case series was to report our experience in a real-life setting of $\geq 1$ dexamethasone intravitreal implants in patients affected by noninfectious intermediate uveitis, posterior uveitis, or panuveitis whose CME was refractory to other steroid therapies.

\section{Methods}

\section{Study design}

This is a prospective, single center, interventional study. All patients signed an informed written consent form before initiation of the procedures performed as per standard of care according to the Italian Ophthalmic Society guidelines. The study was approved by the local Ethic Committee (Comitato Etico A.O.U Città della Salute e della Scienza - A.O. Ordine Mauriziano - A.S.L Città di Torino, protocol no 0033070).

\section{Study population}

Patients of at least 18 years of age with a diagnosis of intermediate or posterior noninfectious inflammatory uveitis or panuveitis with persistent macular edema lasting for $\geq 90$ days refractory to oral or peribulbar steroid treatment were offered long-acting dexamethasone intravitreal implant. Patients had steroid systemic treatment that had to be stable for $\geq 3$ months at the time of the injection. After the dexamethasone intravitreal injection, no systemic treatment was added. All eyes received topical nonsteroidal anti-inflammatory drugs 3 times a day for 1 month following the injection.

Key exclusion criteria were moderate or severe glaucoma not controlled by medical therapy, steroid responder patients (defined as IOP $\geq 30 \mathrm{mmHg}$ or rise of $\geq 15 \mathrm{mmHg}$ after steroid administration), poorly controlled hypertension (defined as systolic pressure $>160 \mathrm{mmHg}$ and diastolic pressure $>90 \mathrm{mmHg}$ ), and poorly controlled diabetes (with $\mathrm{HbA} 1 \mathrm{c}>13 \%)$.

\section{Study treatment}

From November 2011 to January 2014, 12 eyes of 9 patients were included in the study. The dexamethasone intravitreal implant was inserted into the vitreous cavity through the pars plana using a single-use 22-gauge applicator by an experienced ophthalmologist (AMF). Prior to each treatment, the study eye was anesthetized with topical anesthetics and prepared according to standard guidelines of the Italian Ophthalmic Society for intravitreal injection of the longacting dexamethasone implant. All patients were treated with a topical ophthalmic antibiotic 4 times a day starting 3 days prior to the day of their study procedure (day 0 ) and continuing for 5 days after the procedure.

\section{Outcome measures and follow-up}

Patients were evaluated at baseline, 7, 30, 90, 135, and 180 days after the study treatment. The primary outcome at 6 months was improvement of best-corrected visual acuity (BCVA) measured using the standardized Early Treatment Diabetic Retinopathy Study protocol. Secondary outcomes were reduction of central macular thickness (CMT) and improvement of ocular inflammation. Complete slit-lamp biomicroscopy was performed in order to detect nuclear, cortical, or posterior subcapsular lens opacities and signs of inflammation in the anterior chamber (Tyndall effect, cells, flare). IOP was measured with a Goldmann applanation tonometer using a cutoff of $\geq 25 \mathrm{mmHg}$ or a rise of $\geq 20 \%$ compared to the patient's baseline IOP to treat ocular hypertension. Posterior ocular inflammation was evaluated through indirect fundus examination for vitreous haze evaluation and examination of the posterior pole of the retina. Fluorangiography (HRA1; Heidelberg, Germany) was also performed with intravenous fluorescein and indocyanine green taking images of both the posterior pole and retinal periphery during early, mid, and late phases. Measurements of CMT were carried out using optical coherence tomography (OCT; SD-OCT RTV100; Optovue Inc, Fremont, CA, USA).

The primary outcome of BCVA improvement was evaluated using a cutoff of a 15-letter improvement (3 lines on standard visual acuity chart) and a second 10-letter improvement cutoff ( 2 lines on standard visual acuity chart). CMT thickness reduction was considered significant when it reduced $>20 \%$ compared to the initial value.

Eyes were reassessed after 6 months of follow-up to receive a second implant. Eyes with a BCVA improvement of $\geq 10$ letters and/or a decrease in CMT of $\geq 20 \%$ compared to baseline were considered to be responding to the treatment. Eyes with a BCVA improvement of $<10$ letters and those with a CMT reduction $<20 \%$ at OCT were considered as non-responding to the treatment.

\section{Lens status}

The Lens Opacities Classification System (LOCS) III grading system was used to assess the severity of cataract. 
The threshold for referring a patient for cataract surgery was a progression of lens opacity according to the LOCS system associated with reduction of BCVA.

\section{Data analysis and statistical methods}

Mean values of BCVA, CMT, and IOP were recorded at each visit and compared with baseline values using Student's $t$-test for paired samples. An $\alpha$ level of 0.05 was considered statistically significant. Baseline digital photos were taken to evaluate the reduction of ocular inflammation throughout the follow-up and were compared on a clinical basis.

\section{Results}

Patient demographics and baseline characteristics are listed in Table 1.

Mean age was 60.8 years (range 23-78 years), twothird of the patients were male, and the vast majority ( 8 of 9 patients, $88.9 \%$ ) were Caucasians. Seven out of 12 eyes $(58.3 \%)$ were phakic, $4(33.3 \%)$ were pseudophakic, and 1 eye (8.7\%) was aphakic. Epiretinal membranes (ERMs) were present at baseline in 4 eyes, 4 developed it during the follow-up, and in 4 eyes no membranes were observed throughout the whole period. None of the ERMs required surgical intervention. During the visit at day 180, 5 eyes of 5 patients were considered suitable to be reinjected: all of them presented an improvement of both central retinal thickness (CRT) and BCVA. The mean reinjection time was 8.8 months (range 7-10) (Table S1). Seven eyes of 4 patients did not show a significant improvement in BCVA or a reduction in CMT and were not reinjected. Three of these had stable visual acuity at day 180 , whereas in 3 other eyes no significant improvement in BCVA was detected throughout the follow-up. Migration of the implant into the anterior chamber happened in 1 aphakic eye, and thus was not considered suitable for repeated injections.

\section{Visual acuity}

First implant

Mean BCVA changes after 1 dexamethasone intravitreal implant in the 12 eyes considered in this study are shown in Figure 1. Pre-implant mean visual acuity was 20.3 letters $( \pm 15.9)$. It showed significant improvement at all follow-up visits $(p<0.05)$, with a gain of 12 letters $(32.3 \pm 18.1)$ at day 30, 11.9 letters $(32.25 \pm 18.9)$ at day 90, 10.1 letters (30.4 \pm 18.7$)$ at day 135 , and 8 letters $(28.3 \pm 17.9)$ at day 180 . Fifty percent of the eyes ( 6 out of 12) had a 15-letter improvement at day 30 and 90, and 25\% (4 out of 12) at day 135 and 180. Fifty percent of the patients obtained a 10-letter

Table I Patient demographics and baseline characteristics

\begin{tabular}{|c|c|c|c|c|c|c|c|c|}
\hline Patient & Age & Sex & Diagnosis & Therapy & $\begin{array}{l}\text { Basal } \\
\text { BCVA }\end{array}$ & Responders & Lens & $\begin{array}{l}\text { ERM at } \\
\text { baseline }\end{array}$ \\
\hline $\mathrm{I}$ & 55 & $M$ & $\begin{array}{l}\text { RE: idiopatic recurrent } \\
\text { panuveitis }\end{array}$ & $\begin{array}{l}\text { Prednisone } 25 \mathrm{mg} / \text { day } \\
\text { Dexamethasone I drop/day } \\
\text { Methotrexate } 2.5 \mathrm{mg} / \text { week }\end{array}$ & 45 & No & Phakic & No \\
\hline 2 & 75 & M & $\begin{array}{l}\text { RE: idiopatic } \\
\text { granulomatous panuveitis }\end{array}$ & $\begin{array}{l}\text { Dexamethasone } 2 \text { drops/day } \\
\text { Prednisone } 2.5 \mathrm{mg} / \text { day }\end{array}$ & 25 & Yes & Pseudophakic & Yes \\
\hline 3 & 74 & $\mathrm{~F}$ & $\begin{array}{l}\text { LE: recurrent uveitis } \\
\text { with } \mathrm{CMO}\end{array}$ & $\begin{array}{l}\text { Bromfenac } 2 \text { drops/day } \\
\text { Dexamethasone I drop BID } \\
\text { Prednisone } 5 \mathrm{mg} / \text { day }\end{array}$ & I & No & $\begin{array}{l}\text { Surgical } \\
\text { aphakia }\end{array}$ & No \\
\hline 4 & 46 & M & RE: intermediate uveitis & $\begin{array}{l}\text { Prednisone } 25 \text { mg/day } \\
\text { Hydroxychloroquine } 200 \text { mg/day }\end{array}$ & 30 & Yes & Phakic & $\begin{array}{l}\text { No } \\
\text { No }\end{array}$ \\
\hline 5 & 60 & $\mathrm{~F}$ & BE: intermediate uveitis & $\begin{array}{l}\text { Prednisone } 5 \mathrm{mg} / \mathrm{day} \\
\text { Methotrexate } 10 \mathrm{mg} / \text { week } \\
\text { Dexamethasone } 4 \text { drops/day } \\
\text { Subconjunctival triamcinolone } \\
\text { acetonide } 40 \mathrm{mg}\end{array}$ & $\begin{array}{l}47 \\
45\end{array}$ & $\begin{array}{l}\text { No } \\
\text { No }\end{array}$ & $\begin{array}{l}\text { Phakic } \\
\text { Phakic }\end{array}$ & $\begin{array}{l}\text { Yes } \\
\text { Yes }\end{array}$ \\
\hline 6 & 23 & M & $\begin{array}{l}\text { RE: intermediate uveitis } \\
\text { in CMO } \\
\text { LE: vasculitis in Behcet's- } \\
\text { like disease }\end{array}$ & $\begin{array}{l}\text { Prednisone } 10 \mathrm{mg} / \text { day } \\
\text { Cyclosporine A } 200 \mathrm{mg} / \text { day } \\
\text { Azathioprine } 50 \mathrm{mg} / \text { day } \\
\text { Brinzolamide/timolol } 2 \text { drops/day }\end{array}$ & $\begin{array}{l}1 \\
30\end{array}$ & Yes & $\begin{array}{l}\text { Phakic } \\
\text { Phakic }\end{array}$ & $\begin{array}{l}\text { No } \\
\text { No }\end{array}$ \\
\hline 7 & 70 & M & RE: multifocal choroiditis & Netildex 4 drops/day & 5 & No & Phakic & Yes \\
\hline 8 & 78 & $\mathrm{~F}$ & BE: panuveitis & $\begin{array}{l}\text { Prednisone } 5 \mathrm{mg} / \text { day } \\
\text { Dexamethasone } 3 \text { drops/day }\end{array}$ & $\begin{array}{l}20 \\
5\end{array}$ & $\begin{array}{l}\text { Yes } \\
\text { Yes }\end{array}$ & $\begin{array}{l}\text { Pseudophakic } \\
\text { Pseudophakic }\end{array}$ & $\begin{array}{l}\text { Yes } \\
\text { Yes }\end{array}$ \\
\hline 9 & 67 & M & $\begin{array}{l}\text { RE: recurrent uveitis } \\
\text { in sarcoidosis }\end{array}$ & $\begin{array}{l}\text { Prednisone } 5 \mathrm{mg} / \text { day } \\
\text { Cyclosporine } 150 \mathrm{mg} / \text { day } \\
\text { MTX } 10.5 \mathrm{mg} / \text { week }\end{array}$ & 10 & Yes & Phakic & No \\
\hline
\end{tabular}

Abbreviations: RE, right eye; LE, left eye; BE, both eyes; M, male; F, female; ERM, epiretinal membrane; BID, twice a day; CMO, cystoid macular oedema; BCVA, bestcorrected visual acuity. 


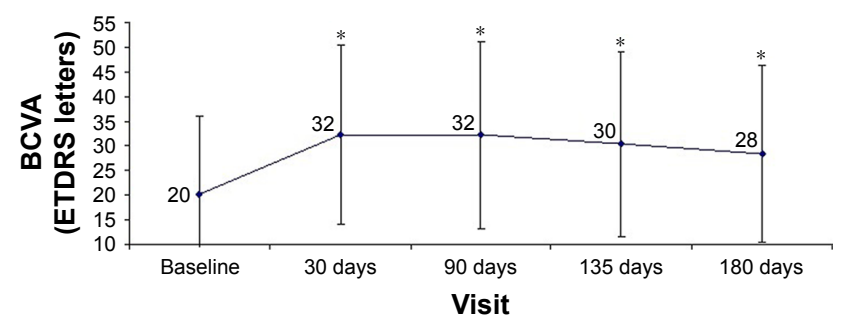

Figure I Changes in BCVA following one dexamethasone intravitreal implant in 12 eyes affected by noninfectious inflammatory uveitis.

Note: *Significant difference between mean values at baseline and follow-up visits. Abbreviations: BCVA, best-corrected visual acuity; ETDRS, Early Treatment Diabetic Retinopathy Study.

improvement at days 30,90, and 135. This was maintained in $33 \%$ of the eyes at day 180 . BCVA improvement maintained its statistical significance when analyzing only the worst eye of patients who received treatment in both eyes (Table S2).

\section{Second implant}

Considering the reinjected eyes, mean visual acuity showed a significant increase of 10.6 letters $(p<0.05)$ after the second implant at day $30(36.4 \pm 10.9$ letters compared to $26 \pm 13.6$ letters at baseline). Although BCVA increased during the entire period with a gain of 9.2 letters ( $35 \pm 14.5$ letters) at 90 days, 7.2 letters ( $33 \pm 14.8$ letters) at 135 days, and 4.2 letters $(30 \pm 14.5$ letters $)$ at 180 days, the difference with baseline values was not statistically significant $(p>0.05)$ (Figure 2).

\section{CMT}

\section{First implant}

Mean CMT was $446.3 \pm 129.9 \mu \mathrm{m}$ at baseline and was significantly reduced throughout the 135 th day of follow-up visit $(p<0.05)$ (Table 2$)$.

In all, $66.7 \%$ ( 8 out of 12 ) of the patients presented a CMT reduction $\geq 20 \%$ compared to mean baseline values until day 135 . This percentage reduced to $33 \%$ at the 6 months

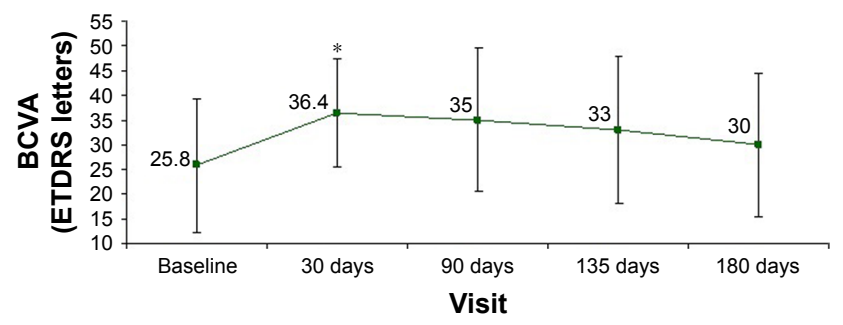

Figure 2 Evolution of BCVA following the second dexamethasone intravitreal implant in 5 eyes.

Note: *Significant difference between mean baseline values and follow-up visits. Abbreviations: BCVA, best-corrected visual acuity; ETDRS, Early Treatment Diabetic Retinopathy Study.
Table 2 Changes in mean CMT following one dexamethasone intravitreal implant, in 12 eyes diagnosed with noninfectious inflammatory uveitis

\begin{tabular}{lll}
\hline CMT $(\mu \mathrm{m})$ & $\begin{array}{l}\text { First implant } \\
\text { (mean } \pm \mathbf{S D} \text { ) }\end{array}$ & p-value \\
\hline Baseline & $446.3 \pm 129.9$ & \\
30 days & $320 \pm 97$ & $<0.05$ \\
90 days & $310.2 \pm 43$ & $<0.05$ \\
I35 days & $313 \pm 45.7$ & $<0.05$ \\
I80 days & $395 \pm 145.3$ & 0.09 \\
\hline
\end{tabular}

Abbreviation: CMT, central macular thickness.

follow-up visit. When analyzing only the worst eyes of those patients who received treatment in both eyes, the CMT was significantly reduced until day $135(p<0.05)$ (Table S2).

\section{Second implant}

CMT at baseline was 493.2 $\pm 134.6 \mu \mathrm{m}$. At day 30, CMT was reduced to $360.8 \pm 134.6 \mu \mathrm{m}$, to $371.6 \pm 102.3 \mu \mathrm{m}$ at 90 days, to $445.8 \pm 157.7 \mu \mathrm{m}$ at 135 days, to $462.8 \pm 187.5 \mu \mathrm{m}$ at 180 days $(p>0.05)$ (Table 3$)$. CMT reductions after the second injection showed a similar pattern when compared to the first injection, though differences between the 2 groups were not statistically significant.

\section{IOP}

Following the first implant, mean IOP at baseline was $11.91 \pm 3.57 \mathrm{mmHg}$. It rose to $13.75 \pm 4.24 \mathrm{mmHg} 30$ days after the procedure, to $14.33 \pm 5.10 \mathrm{mmHg}$ at day 90 , to $13 \pm 3.41 \mathrm{mmHg}$ at day 135 , and to $13.91 \pm 2.06 \mathrm{mmHg}$ at 6 months follow-up. These variations never appeared to be statistically significant $(p>0.05)$. An IOP $\geq 25 \mathrm{mmHg}$ was not observed during the first implant.

After the second implant, IOP was higher at 30 days $(17 \pm 7.77 \mathrm{mmHg})$ compared to pre-implant values (14.6 \pm 5.4 $\mathrm{mmHg}$ ). This was due to a single eye which developed an IOP of $30 \mathrm{mmHg}$ at day 30 and was successfully treated with topical therapy (brinzolamide $10 \mathrm{mg} / \mathrm{mL}+$ timolol $5 \mathrm{mg} / \mathrm{mL}$ ) until the following visit at day 90.

Table 3 Changes in mean CMT following a second dexamethasone intravitreal implant in 5 eyes diagnosed with noninfectious inflammatory uveitis

\begin{tabular}{lll}
\hline CMT $(\mu \mathrm{m})$ & $\begin{array}{l}\text { Second implant } \\
(\text { mean } \pm \text { SD) }\end{array}$ & $p$-value \\
\hline Baseline & $493.2 \pm 135$ & \\
30 days & $360 \pm 112$ & 0.06 \\
90 days & $371.6 \pm 102.3$ & 0.06 \\
135 days & $446 \pm 157.8$ & 0.08 \\
I80 days & $462.8 \pm 188$ & 0.4 \\
\hline
\end{tabular}

Abbreviation: CMT, central macular thickness. 


\section{Lens status}

Cataract progression was observed in 4 of 8 phakic eyes (50\%) after the first dexamethasone intravitreal implant, and in 2 of 3 phakic eyes following the second implant, with 1 eye requiring cataract surgery with posterior chamber intraocular lens implant.

\section{Anterior chamber migration}

Migration into the anterior chamber of the device was observed 24 hours after the injection in the only aphakic patient. This complication was handled with pupil dilation and postural maneuvres, enabling repositioning of the implant in the vitreous chamber (Figure S1).

\section{Repeat injections of dexamethasone}

Mean BCVA values of the 5 patients who underwent the first and the second implant are plotted in Figure 3. For those patients who received 2 dexamethasone intravitreal implants, mean values of BCVA and CMT were compared for the baseline and for each subsequent visit. Mean visual acuity at baseline was better before the second implant compared to initial visual acuity prior to the first implant. There was a 9.6-letter improvement (16.2 letters before first implant and 25.8 letters before second implant); this difference was statistically significant $(p<0.05)$. All the following visits showed a greater BCVA after the second device implant compared to the first one (36.4 vs 33.6 letters at 30 days, 35 vs 32.2 letters at 90 days, 33.4 vs 30 letters at 135 days, 31.4 vs 28 letters at 180 days), but none were statistically significant. CMT of the first implant was $504.4 \mu \mathrm{m}$ at baseline, $373 \mu \mathrm{m}$ at 30 days, $319.4 \mu \mathrm{m}$ at 90 days, $348.6 \mu \mathrm{m}$ at 135 days, and $485 \mu \mathrm{m}$ at 180 days, whereas during the second treatment it reached 493.2, 360.8, 371.6, 445.8, and $462.8 \mu \mathrm{m}$, respectively. These differences were not statistically significant.

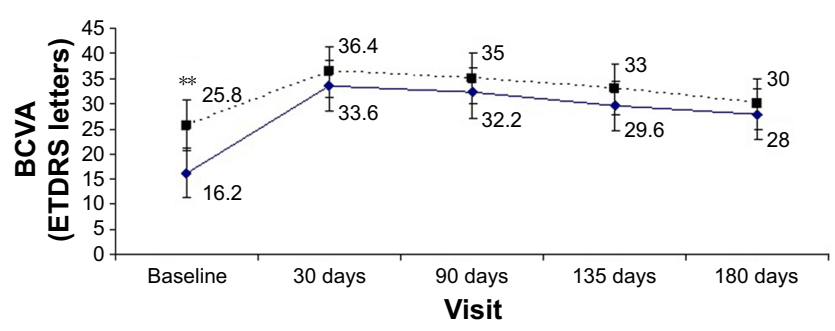

Figure 3 Best-corrected mean visual acuity after I dexamethasone intravitreal implant in 5 eyes of 5 patients who responded to treatment.

Notes: **The difference between mean baseline values showed statistical difference. First implant: straight line, second implant: dotted line.

Abbreviations: BCVA, best-corrected visual acuity; ETDRS, Early Treatment Diabetic Retinopathy Study.

\section{Vitreoretinal interface}

Six eyes out of $12(50 \%)$ demonstrated abnormalities of the vitreo-macular interface, ranging from subtle thickening without traction (5 eyes, $41 \%$ ) to ERMs. We did not notice a progression of the ERM during follow-up. In all these cases, after the implant the membranes followed the shape of the retina suggesting that the tractional role was minimal (Figures S2-S4).

\section{Conclusion}

Blindness is attributed to uveitis in $10 \%-15 \%$ of cases in the developed world. ${ }^{1}$ One of the most common complications is CME, which may be particularly difficult to treat. Its chronicity accounts for severe visual loss, occurring in $25 \%-50 \%$ of patients. ${ }^{2-4}$

In this study, we examined the effect of repeated intravitreal injections of $0.7 \mathrm{mg}$ long-acting dexamethasone in eyes with recalcitrant macular edema secondary to noninfectious inflammatory uveitis in a clinical setting. All eyes had undergone at least one line of therapy, with oral steroids and/or immunosuppressive medications, without any effect on the macular edema.

After the first implant, we found 1) a significant improvement of BCVA through the entire 6 month follow-up period, 2) a significant reduction of CMT until day 135 , with a thickness increase observed at 180 days, 3) a safety profile consistent with the other studies, and 4) a case of anterior chamber dislocation in aphakic eye, successfully treated with postural maneuvres.

The HURON study ${ }^{22}$ examined the use of a single dexamethasone implant in cases of chronic noninfectious uveitis, showing an improvement in BCVA and vitritis accompanied by a decrease in CRT. In the 77 eyes receiving $0.7 \mathrm{mg}$ longacting dexamethasone, the mean visual acuity was 58 letters at baseline, with $46.2 \%$ of eyes achieving a $\geq 15$-letter improvement at 6 months $(p<0.001)$. In an observational case series on repeat dexamethasone implants in noninfectious uveitis by Tomkins-Netzer et al, ${ }^{25}$ the mean baseline visual acuity was 0.47 and 0.43 at 6 months. Zarranz-Ventura et $\mathrm{a}^{26}$ reported in another multicenter retrospective cohort study a visual acuity of $0.68 \log$ MAR at baseline, significantly improving to 0.6 $\operatorname{logMAR}$ at 6 months. In our cohort, pre-implant BCVA, with a mean value of $20.3( \pm 15.9)$ letters, significantly improved to $28.3 \pm 17.9$ letters $(p<0.05)$ at 6 months, and 4 out of 12 eyes $(25 \%)$ showed a 15 -letter improvement at the same time point. These values seem to be more in line with retrospective studies, ${ }^{25,26}$ having patient inclusion criteria not as strict as those found in randomized trials. ${ }^{22} \mathrm{CRT}$ was significantly 
reduced initially, increasing subsequently at 6 months. A similar trend was noted by Nobre-Cardoso et al, ${ }^{27}$ where the relapse of macular edema occurred at 3 months after the first injection.

Following our re-treatment criteria, 6 eyes were not treated: 3 eyes because the patients responded to the first implant without a recrudescence of the disease at 180 days; and 3 other eyes because the reduction of CMT was not associated with an improvement of visual acuity during the follow-up. Repeated injections achieved a BCVA gain similar to the first implant throughout the entire period, a reduction in CMT that was stable during the follow-up, although not statistically significant. Comparing the follow-up visits of the first and second implant, we noticed that functional improvement was similar, whereas the time trend of CMT differed. As the first treatment induced an initial CMT reduction followed by a relapse of macular edema, the second implant stabilized it at lower values during the whole follow-up. Other studies found a better functional and anatomical profile before the second implant in eyes receiving multiple injections. ${ }^{27,28}$

The risk of increased IOP is a well-known side effect after dexamethasone intravitreal implant, ${ }^{10,11,18}$ and in nonsteroid responders it can be effectively managed with topical therapy. ${ }^{22,25-27}$ In our cohort, 1 out of 12 eyes had an IOP $>21 \mathrm{mmHg}(8.3 \%)$ after the first injection and 1 out of 5 eyes had an IOP $>25 \mathrm{mmHg}(20 \%)$ after the second injection. Both were effectively treated with local IOP lowering medication. The rate of this complication was similar to that found by Tomkins-Netzer et al $(7.9 \%$ after first implant, $17.4 \%$ after second implant), and lower compared with other studies. ${ }^{26,27}$ Cataract progression occurred in 4 out of 8 phakic eyes after the first implant and in 2 out of 3 phakic eyes after the second implant; in both cases, cataract surgery was required. The rates of cataract incidence vary by a considerable degree, with $50 \%$ of eyes developing cataract in the study published by Arcinue et al, ${ }^{29}$ to $4.9 \%$ in the HURON study, ${ }^{22}$ or $7 \%$ in the retrospective analysis of 47 eyes. ${ }^{27}$ We estimate that the cohort of phakic patients in this study is too scarce to be comparable to other studies. Anterior chamber migration of the device is an adverse event reported in the literature and one of the risks underlined in the Food and Drug Administration Safety Report for aphakic and (anterior chamber intraocular lens) AC-IOL eyes. ${ }^{31-34}$ In our series, the anterior chamber displacement occurred in the only aphakic eye of our study and it was successfully managed with postural maneuvres. Evidence of complications in aphakic patients and AC-IOLs is stronger at present, ${ }^{35}$ while this was not the case during the inclusion of patients in this study. Before the first injection, 8 of 12 eyes $(66 \%)$ presented with an ERM, without metamorphopsia or traction. The implant proved effective in reducing the macular thickness even in the presence of ERM and determined a functional improvement. In a few cases reported in the literature, intravitreal dexamethasone implant in association with a vitreo-macular traction resulted in the formation of a macular hole or pseudohole. ${ }^{36,37}$ In our study, no macular hole presented over the 26 months study.

This paper had some limitations especially concerning the less number of patients and the absence of a control group to compare the results. Also, a longer follow-up with a higher reinjection frequency would allow to detect changes and side effects more accurately.

In conclusion, this single-arm interventional prospective study illustrates how dexamethasone intravitreal implant in uveitic patients with refractory macular edema can be used effectively in a clinical setting. It also shows that in patients with alterations of the vitro-macular interface, the implant can be effective in reducing the macular thickness before any surgical therapy is attempted. Patients with recurrent macular edema may benefit from a second implant although some of them can show an increase of IOP. Further randomized studies are needed to evaluate the role of dexamethasone multiple implant on cataract development.

\section{Disclosure}

The authors report no conflicts of interest in this work.

\section{References}

1. Rothova A, Suttorp-van Schulten MS, Frits Treffers W, Kijlstra A. Causes and frequency of blindness in patients with intraocular inflammatory disease. Br J Ophthalmol. 1996;80:332-336.

2. Nussenblatt RB. The natural history of uveitis. Int Ophthalmol. 1990; 14(5-6):303-308.

3. Thomkins-Netzer O, Talat I, Bar A, et al. Long-term clinical outcome and causes of visual loss in patients with uveitis. Ophthalmology. 2014; 121:2387-2392.

4. de Smet MD, Taylor SR, Bodaghi B, et al. Understanding uveitis: the impact of research on visual outcomes. Prog Retin Eye Res. 2011;30: 452-470.

5. Jabs DA, Nussenblatt RB, Rosenbaum JT. Standardization of uveitis nomenclature for reporting clinical data. Results of the First International Workshop. Am J Ophthalmol. 2005;140:509-516.

6. Kempen JH, Sugar EA, Jaffe GJ, et al. Fluorescein angiography versus optical coherence tomography for diagnosis of uveitic macular edema. Ophthalmology. 2013;120:1852-1859.

7. Freeman G, Matos K, Pavesio CE. Cystoid macular oedema in uveitis: an unsolved problem. Eye (Lond). 2001;15:12-17.

8. Jap A, Chee SP. Immunosuppressive therapy for ocular diseases. Curr Opin Ophthalmol. 2008;19(6):535-540.

9. Jabs DA, Rosenbaum JT, Foster CS, et al. Guidelines for the use of immunosuppressive drugs in patients with ocular inflammatory disorders: recommendations of an expert panel. Am J Ophthalmol. 2007;144:812-817. 
10. Fardet DL, Kassar A, Cabane J, Flahault A. Corticosteroid-induced adverse events in adults. Drug Saf. 2007;30:861-881.

11. Armaly MF. Statistical attributes of the steroid hypertensive response in the clinically normal eye. I. The demonstration of three levels of response. Invest Ophthalmol. 1965;4:187-197.

12. Armaly MF. Effect of corticosteroids on intraocular pressure and fluid dynamics. II. The effect of dexamethasone in the glaucomatous eye. Arch Ophthalmol. 1963;70:492-499.

13. Bakri SJ, Beer PM. The effect of intravitreal triamcinolone acetonide on intraocular pressure. Ophthalmic Surg Lasers Imaging. 2003;34: 386-390.

14. Kogure A, Ohkoshi K, Kogure S, Yamaguchi T, Kishi S. Efficacy and retention times of intravitreal triamcinolone acetonide for macular edema. Jpn J Ophthalmol. 2008;52:122-126.

15. Konstantopoulos A, Williams CP, Newsom RS, Luff AJ. Ocular morbidity associated with intravitreal triamcinolone acetonide. Eye. 2007; 21:317-320.

16. Nguyen QD, Callan D, Dugel P, Godfrey DG, Goldstein DA, Wilensky JT. Treating chronic non-infectious posterior segment uveitis: the impact of cumulative damage. Proceedings of an expert panel roundtable discussion. Retina. 2006;26(Suppl 8):1-6.

17. Karim R, Sykakis E, Lightman S, Fraser-Bell S. Interventions for the treatment of uveitic macular edema: a systematic review and metaanalysis. Clin Ophthalmol. 2013;7:1109-1144.

18. Haller JA, Bandello F, Belfort R Jr, et al; OZURDEX GENEVA Study Group. Randomized, sham-controlled trial of dexamethasone intravitreal implant in patients with macular edema due to retinal vein occlusion. Ophthalmology. 2010;117(6):1134-1146.

19. Haller JA, Bandello F, Belfort R Jr, et al; OZURDEX GENEVA Study Group. Dexamethasone intravitreal implant in patients with macular edema related to branch or central vein occlusion: twelve-month study results. Ophthalmology. 2011;118(12):2453-2460.

20. Kuppermann BD, Blumenkranz MS, Haller JA, et al; Dexamethasone DDS Phase II Study Group. Randomized controlled study of an intravitreous dexamethasone drug delivery system in patients with persistent macular edema. Arch Ophthalmol. 2007;125(3): 309-317.

21. Hunter RS, Lobo AM. Dexamethasone intravitreal implant for the treatment of noninfectious uveitis. Clin Ophthalmol. 2011;5: 1613-1621.

22. Lowder C, Belfort R, Lightman S, et al. Dexamethasone intravitreal implant for noninfectious intermediate or posterior uveitis. Arch Ophthalmol. 2011;129:545-553.

23. Haller JA, Dugel P, Weinberg DV, Chou C, Whitcup SM. Evaluation of the safety and performance of an applicator for a novel intravitreal dexamethasone drug delivery system for the treatment of macular edema. Retina. 2009;29:46-51.
24. Chang-Lin JE, Attar M, Acheampong AA, et al. Pharmacokinetics and pharmacodynamics of a sustained-release dexamethasone intravitreal implant. Invest Ophthalmol Vis Sci. 2011;52(1):80-86.

25. Tomkins-Netzer O, Taylor SRJ, Bar A, et al. Treatment with repeat dexamethasone implants results in long-term disease control in eyes with noninfectious uveitis. Ophthalmology. 2014;121:1649-1654.

26. Zarranz-Ventura J, Carreno E, Johnston RL, et al. Multicenter study of intravitreal dexamethasone implant in noninfectious uveitis: indications, outcomes, and reinjection frequency. Am J Ophthalmol. 2014; 158:1136-1145.

27. Nobre-Cardoso J, Champion E, Darugar A, Fel A, Lehoang P, Bodaghi B. Treatment of non-infectious uveitic macular edema with the intravitreal dexamethasone implant. Ocul Immunol Inflamm. Epub 2016 Mar 22.

28. Cao JH, Mulvalhill M, Zhang L, Joondeph BC, Dacey MF. Dexamethasone intravitreal implant in the treatment of persistent uveitic macular edema in the absence of active inflammation. Ophthalmology. 2014;121:1649-1654.

29. Arcinue CA, Ceròn OM, Foster CS. A comparison between the fluocinolone acetonide (Retisert) and dexamethasone (Ozurdex) intravitreal implants in uveitis. J Ocul Pharmacol Ther. 2013;29:501-507.

30. Multicenter Uveitis Steroid Treatment Research Group. The multicenter uveitis steroid treatment (MUST) trial: rationale, design and baseline characteristics. Am J Ophthalmol. 2010;149(4):550-556.

31. Adeniran JMF, Jusufbegovic D, Schaal S. Common and rare ocular side-effects of the dexamethasone implant. Ocul Immunol Imflamm. Epub 2016 Jul 5.

32. Kishore SA, Schaal S. Management of anterior chamber dislocation of dexamethasone implant. Ocul Immunol Inflamm. 2013;21(1):90-91.

33. Pardo-López D, Francés-Muñoz E, Gallego-Pinazo R, Díaz-Llopis M. Anterior chamber migration of dexamethasone intravitreal implant (Ozurdex ${ }^{\circledR}$ ). Graefes Arch Clin Exp Ophthalmol. 2012;250(11): 1703-1704.

34. Marín-Lambíes C, Gallego-Pinazo R, García-Delpech S, Díaz-Llopis M. Ozurdex ${ }^{\circledR}$ y afaquia: una combinaciòn a evitar [Ozurdex $\left({ }^{\circledR}\right)$ and aphakia: a combination to avoid]. Arch Soc Esp Oftalmol. 2012;87(6):191-192. Spanish.

35. Burkholder BM, Moradi A, Thorne JE, Dunn JP. The dexamethasone intravitreal implant for noninfectious uveitis: practice patterns among uveitis specialists. Ocul Immunol Inflamm. 2015;23(6):444-453.

36. Di Antonio L, Toto L, Carpineto P, Mastropasqua A, De Nicola C, Mastropasqua L. Macular pseudohole development after sustainedrelease dexamethasone intravitreal implant for macular edema due to central retinal vein occlusion. Eur J Ophthalmol. 2014;24(1):134-137.

37. De Benedetto U, Battaglia Parodi M, Knutsson KA, Lattanzio R, Bandello F, Iacono P. Macular hole after injection of intravitreal implant for macular oedema due to central retinal vein occlusion. Acta Ophthalmol. 2013;91(1):e75-e77. 


\section{Supplementary materials}

Table SI Eyes receiving the first and second dexamethasone intravitreal implant, and the mean interval between injections

\begin{tabular}{lll}
\hline $\begin{array}{l}\text { Study eyes and } \\
\text { reinjection } \\
\text { interval }\end{array}$ & $\begin{array}{l}\text { First dexamethasone } \\
\text { intravitreal implant }\end{array}$ & $\begin{array}{l}\text { Second dexamethasone } \\
\text { intravitreal implant }\end{array}$ \\
\hline $\begin{array}{l}\text { Study eyes } \\
\text { Reinjection interval, }\end{array}$ & 0 & 5 \\
mean (range) & $8.8(7-10)$ \\
months & \\
\hline
\end{tabular}

Table 52 Changes in BCVA and CMT following one dexamethasone intravitreal implant in 9 eyes affected by noninfectious inflammatory uveitis, considering only the worst eye for patients receiving treatment in both eyes

\begin{tabular}{lll}
\hline $\begin{array}{l}\text { Study } \\
\text { visit }\end{array}$ & $\begin{array}{l}\text { BCVA (ETDRS letters) } \\
\text { mean } \pm \text { SD ( } p \text {-value) }\end{array}$ & $\begin{array}{l}\text { CMT }(\mu \mathrm{m}) \\
(\boldsymbol{p} \text {-value) }\end{array}$ \\
\hline Baseline & $17.1 \pm 16.6$ & $446.7 \pm I 27$ \\
30 days & $28 \pm 18.6$ & $326.4 \pm I I 2$ \\
& $(0.01)$ & $(0.005)$ \\
90 days & $30 \pm 20$ & $315.7 \pm 46.4$ \\
& $(0.004)$ & $(0.006)$ \\
135 days & $28 \pm 19.5$ & $317.3 \pm 47$ \\
& $(0.008)$ & $(0.009)$ \\
I80 days & $25 \pm 18.5$ & $398 \pm 140$ \\
& $(0.02)$ & $(0.23)$ \\
\hline
\end{tabular}

Abbreviations: BCVA, best-corrected visual acuity; CMT, central macular thickness; ETDRS, Early Treatment Diabetic Retinopathy Study.
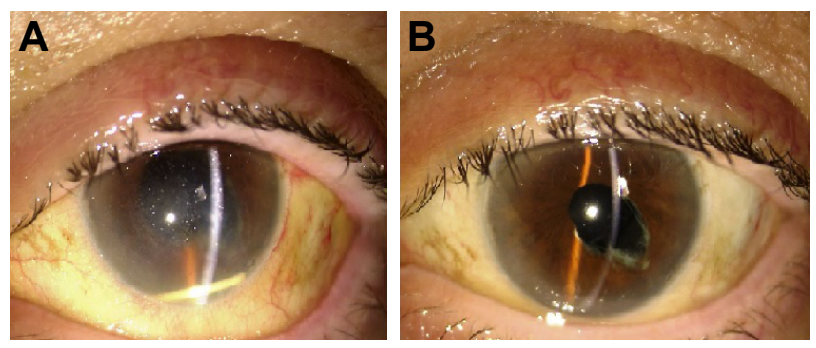

Figure SI Anterior chamber migration of the long-acting intravitreal dexamethasone implant with corneal edema in an aphakic patient.

Notes: Postural maneuvres with previous pupil dilation allowed correct repositioning of the implant with full resolution of the corneal edema and restoration of the VA before the complication. (A) Migration of the dexamethasone intravitreal implant into the anterior chamber. (B) Resolution of corneal edema after repositioning of the device into the vitreous chamber.

Abbreviation: VA, visual acuity.

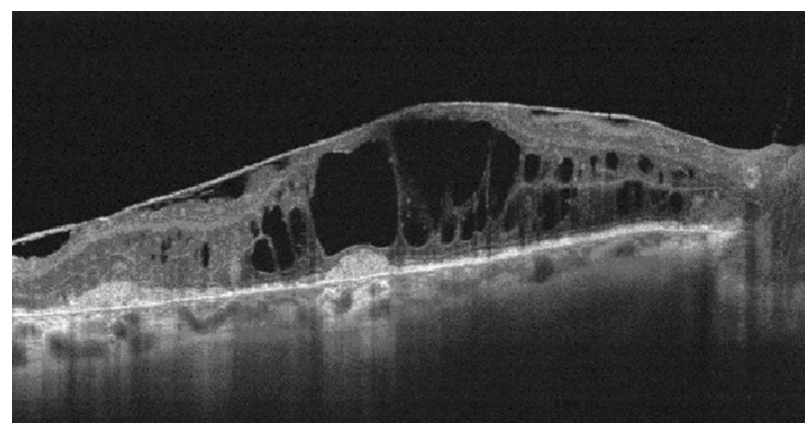

Figure S2 OCT image of an epiretinal membrane 30 days after intravitreal dexamethasone injection.

Abbreviation: OCT, optical coherence tomography.

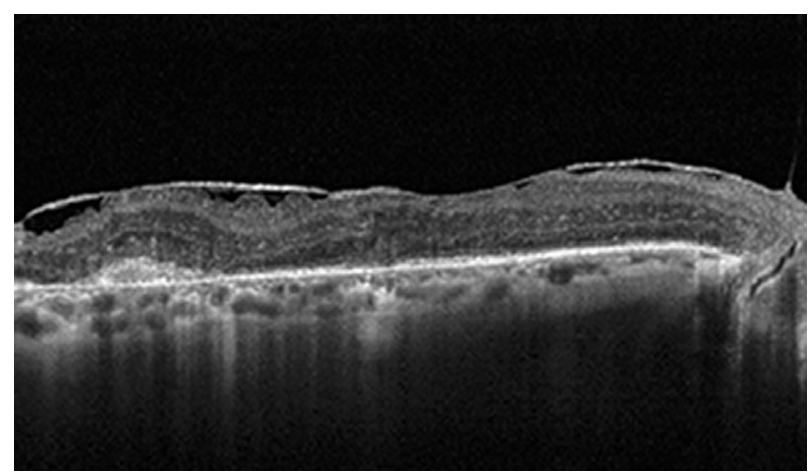

Figure S3 OCT image of an epiretinal membrane 90 days after intravitreal dexamethasone injection.

Abbreviation: OCT, optical coherence tomography

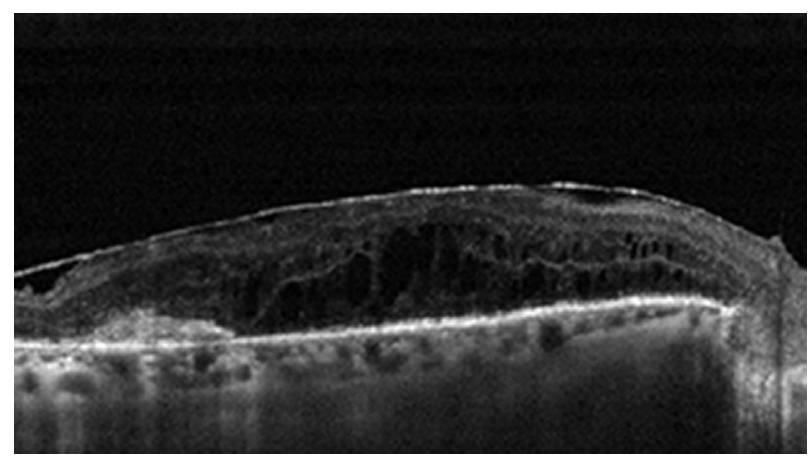

Figure S4 OCT image of an epiretinal membrane 180 days after intravitreal dexamethasone injection.

Abbreviation: OCT, optical coherence tomography.
Clinical Ophthalmology

\section{Publish your work in this journal}

Clinical Ophthalmology is an international, peer-reviewed journal covering all subspecialties within ophthalmology. Key topics include: Optometry; Visual science; Pharmacology and drug therapy in eye diseases; Basic Sciences; Primary and Secondary eye care; Patient Safety and Quality of Care Improvements. This journal is indexed on

Submit your manuscript here: http://www.dovepress.com/clinical-ophthalmology-journal

\section{Dovepress}

PubMed Central and CAS, and is the official journal of The Society of Clinical Ophthalmology (SCO). The manuscript management system is completely online and includes a very quick and fair peer-review system, which is all easy to use. Visit http://www.dovepress.com/ testimonials.php to read real quotes from published authors. 